The authors reported no conflicts of interest.

The Journal policy requires editors and reviewers to disclose conflicts of interest and to decline handling or reviewing manuscripts for which they may have a conflict of interest. The editors and reviewers of this article have no conflicts of interest.

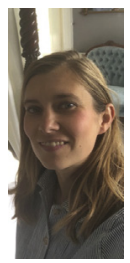

\section{THE IMPORTANCE OF CORONAVIRUS DISEASE 2019 TESTING IN CARDIAC SURGERY \\ To the Editor:}

The extraordinary demands for managing patients with Coronavirus Disease 2019 (COVID19) has altered the Italian hospitals' ability to provide adequate care. With exponential increase of the COVID19 population and a progressive reduction of resources, the ability to provide surgical care has been rapidly decreased. ${ }^{1}$ Although several surgical organizations developed guides for triaging patents with cancer, the selection of candidates for cardiac surgery poses major challenges given the rapid progression of the underlying disease and the uncertain evolution of organ failure. ${ }^{2,3}$

Haft and colleagues ${ }^{4}$ provided an important guidance to adult cardiac surgeons regarding the triage of patients with cardiac disease. The document presents some useful general rules to optimize hospital resources. ${ }^{4}$ However, little attention is still given to these frail patients at high risk for COVID-19 infection and dissemination. Moreover, no clear indication exists regarding the preoperative screening tests to be performed before surgery with significant variations in practice according to each institution. ${ }^{4}$ Our department of cardiac surgery is a tertiary referral center providing cardiac service to approximately 660,000 people in the region of Piedmont, in the northwest of Italy. Our hospital was initially COVID-19 free, but, given the large increase of infected patients, it was rapidly involved in the management of these patients. However, as per hospital policy, patients admitted for cardiac surgery were not tested for COVID-19 because they were receiving elective but not deferrable surgery. From February 1 to April 15,100 patients were admitted to our cardiac surgery department. They were all symptomatic with a high prevalence of

\footnotetext{
The Editor welcomes submissions for possible publication in the Letters to the Editor section that consist of commentary on an article published in the Journal or other relevant issues. Authors should: • Include no more than 500 words of text, three authors, and five references. • Type with double-spacing. • See http://jtcs.ctsnetjournals.org/ misc/ifora.shtml for detailed submission instructions. • Submit the letter electronically via jtcvs.editorialmanager.com. Letters commenting on an article published in the JTCVS will be considered if they are received within 6 weeks of the time the article was published. Authors of the article being commented on will be given an opportunity of offer a timely response ( 2 weeks) to the letter. Authors of letters will be notified that the letter has been received. Unpublished letters cannot be returned.
}

New York Heart Association III or at high risk for rapidly progressive disease. At hospital admission, patients received routine laboratory tests and chest x-ray but no specific test for COVID-19. No patient showed any COVID-19-related symptoms at the time of surgery. Among operated patients, 4 of them developed symptomatic COVID-19 infection during hospitalization. One of them required intensive care unit admission. In the same time period, 5 of 8 cardiac surgeons, 1 of 9 cardiac anesthesiologists, and 7 of 48 nurses became COVID-19 positive and symptomatic. This has progressively led to a dramatic reduction in the department activity, with a $75 \%$ of reduction of the daily surgical and clinical caseload. Such dispersion of resources has consequently led to decentralization of care and a delay of surgical treatment, with $6.6 \%$ of patients who died while on the waiting list. Thus, our healthcare institutions should focus more on the triage of patients with cardiac disease, considered at high risk of COVID-19 infection. These patients should mandatorily receive microbiological tests for COVID-19, even in the presence of unstable conditions, to decrease the risk of viral dissemination and depletion of resources.

Giulia Maj, $M D^{a}$ Antonio Campanella, $M D^{b}$ Andrea Audo, $M D^{b}$

${ }^{a}$ Departments of Anesthesia and Intensive Care

${ }^{b}$ Cardiac Surgery

Azienda Ospedaliera SS. Antonio e Biagio e Cesare Arrigo

Alessandria, Italy

\title{
References
}

1. Zangrillo A, Beretta L, Silvani P, Colombo S, Scandroglio AM, Dell'Acqua A, et al. Fast reshaping of intensive care unit facilities in a large metropolitan hospital in Milan, Italy: facing the COVID-19 pandemic emergency. Crit Care Resusc. April 1, 2020 [Epub ahead of print].

2. COVID-19 guidance for triage of operations for thoracic malignancies: a consensus statement from thoracic surgery outcomes research network. Thoracic Surgery Outcomes Research Network, Inc. Ann Thorac Surg. April 4, 2020 [Epub ahead of print].

3. Drake D, Morrow CD, Kinlaw K, De Bonis M, Zangrillo A, Sade RM. Cardiothoracic surgeons in pandemics: ethical considerations. Ann Thorac Surg. April 9, 2020 [Epub ahead of print].

4. Haft JW, Atluri P, Alawadi G, Engelman D, Grant MC, Hassan A, et al. Adult cardiac surgery during the COVID-19 Pandemic: a tiered patient triage guidance statement. Ann Thorac Surg. April 10, 2020 [Epub ahead of print].

https://doi.org/10.1016/j.jtcvs.2020.04.117

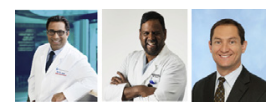

\section{REPLY: HAVE WE DONE THE BEST THAT WE COULD HAVE DONE? \\ Reply to the Editor:}

In their letter to the editor, ${ }^{1}$ Maj and colleagues cited the recently published guidance document on cardiac surgical triaging during the coronavirus 2019 (COVID-19) pandemic by Haft and colleagues ${ }^{2}$ and raised the following points: (1) 
Dr Arora holds an unrestricted educational grant from Pfizer Canada, Inc, and Honoraria from Mallinckrodt Pharmaceuticals, Abbott Nutrition, and Edwards Lifesciences unrelated to the present communication. All other authors reported no conflicts of interest.

The Journal policy requires editors and reviewers to disclose conflicts of interest and to decline handling or reviewing manuscripts for which they may have a conflict of interest. The editors and reviewers of this article have no conflicts of interest.

the absence of patient frailty as part of the triaging process, (2) the potential collateral impact of deferring patients on the cardiac surgery wait list during the pandemic, and (3) the value of routine preoperative COVID-19 testing in protecting both patients and health care workers.

First, frailty is a well-established risk factor for increased morbidity and mortality following cardiac surgery. ${ }^{3}$ The recently-published National Institute for Health and Care Excellence (NICE) guidelines have incorporated a measure of frailty to guide clinical decisions in critically ill adults. ${ }^{4}$ We acknowledge that frail patients are likely at increased risk for contracting COVID-19 (with an as of yet-to-be determined impact on outcomes) and that frailty should be considered when triaging patients both during the surgical deferral phase of the pandemic and as part of the "ramping back up" phase when the COVID-19 curves begin to flatten.

Second, delay in definitive therapy for certain cardiovascular diseases may yield major adverse cardiac consequences, including myocardial infarction, decline in ventricular function, or sudden death. As such, we must re-emphasize that for those patients in whom procedures are being delayed and in whom alternative therapies are not deemed appropriate, there is a critical need to proactively monitor every patient on the surgical wait-list for progression of symptoms. ${ }^{2}$

Finally, we are saddened by Maj and colleagues' accounts of COVID-19 infection at their institution, first in those patients with advanced cardiovascular disease who, despite not having viral symptoms on admission, eventually tested positive for COVID-19, and second, among the cardiac surgeons, cardiac anesthesiologists, and nurses who tested positive while serving on the frontlines. Many have advocated for routine testing in an effort to mitigate the risk of COVID-19 infection and transmission, but there remains, at present, $\mathrm{NO}$ test available that can reliably rule out COVID-19, particularly in the asymptomatic patient. ${ }^{5}$ Rather, testing must be complemented by well-established risk-reduction strategies, including frequent screening, handwashing, physical distancing, use of personal protective equipment, and isolation of those at risk. Only then will hospitals be able to provide a safe environment for their patients and their health care providers in the "post-lockdown, pre-vaccine" phase of the pandemic. ${ }^{6}$

Cardiac surgeons from across the world have drastically changed their clinical practices in response to the COVID19 pandemic, and while published guidance statements have provided a template by which these changes could be carried out, they have not always accounted for the differences that often exist between institutions, regions, and countries. The letter by Maj and colleagues highlights the realities that some of us face, and it is up to the global cardiac surgical community to share knowledge, experiences, and collect data to determine best practices so that we may care for our patients and for each other to the best of our abilities.

\section{Rakesh C. Arora, MD, PhD, FRCSC $C^{a, b}$ Ansar Hassan, MD, $P h D^{c}$ \\ Jonathan W. Haft, $M D^{d}$}

on behalf of the Society of Thoracic Surgeons COVID-19

Taskforce

${ }^{a}$ Department of Surgery

Max Rady College of Medicine

University of Manitoba

Winnipeg, Manitoba, Canada

${ }^{b}$ Cardiac Sciences Program

St Boniface Hospital

Winnipeg, Manitoba, Canada

${ }^{c}$ Department of Cardiac Surgery

New Brunswick Heart Centre

Saint John, New Brunswick, Canada

${ }^{d}$ Department of Cardiac Surgery

University of Michigan

Ann Arbor, Mich

The authors acknowledge the contribution of all the members of the Society of Thoracic Surgeons COVID-19 Taskforce to this document (in alphabetical order): Gorav Ailawadi, MD, Pawan Atluri, MD, Daniel T. Engelman, MD, Michael C. Grant, MD, Isaac George, MD, Jean- Francois Legare, MD MSc, Sylvain Lother, MD, and Glenn Whitman.

\section{References}

1. Maj G, Campanella A, Audob A. The importance of COVID-19 testing in cardiac surgery. J Thorac Cardiovasc Surg. 2020;160:e149.

2. Haft JW, Atluri P, Alawadi G, Engelman D, Grant MC, Hassan A, et al. Adult cardiac surgery during the COVID-19 pandemic: a tiered patient triage guidance statement. Ann Thorac Surg. April 10, 2020 [Epub ahead of print].

3. Sepehri A, Beggs T, Hassan A, Rigatto C, Shaw-Daigle C, Tangri N, et al. The impact of frailty on outcomes after cardiac surgery: a systematic review. J Thorac Cardiovasc Surg. 2014;148:3110-7.

4. National Institute of Health and Care Excellence. Overview | COVID-19 rapid guideline: critical care in adults | Guidance | NICE. 2020. Available at: https:// www.nice.org.uk/guidance/ng159. Accessed July 9, 2020. 
5. Hassan A, Arora RC, Lother SA, Adams C, Bouchard D, Cook R, et al. Ramping up the delivery of cardiac surgery during the COVID-19 pandemic: a guidance statement from the Canadian Society of Cardiac Surgeons. Can J Cardiol. April 29, 2020 [Epub ahead of print].

6. Engelman DT, Lother S, George I, Funk DJ, Ailawadi G, Atluri P, et al. Adult cardiac surgery and the COVID-19 pandemic: aggressive infection mitigation strate- gies are necessary in the operating room and surgical recovery. Ann Thorac Surg April 27, 2020 [Epub ahead of print].

https://doi.org/10.1016/j.jtcvs.2020.05.071 